\title{
A transcriptomic and proteomic atlas of expression in the Nezara viridula (Heteroptera: Pentatomidae) midgut suggests the compartmentalization of xenobiotic metabolism and nutrient digestion
}

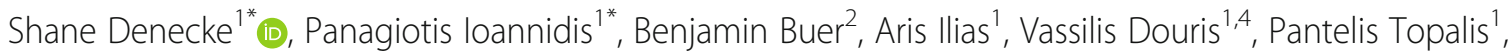
Ralf Nauen², Sven Geibel ${ }^{2}$ and John Vontas ${ }^{1,3}$

\begin{abstract}
Background: Stink bugs are an emerging threat to crop security in many parts of the globe, but there are few genetic resources available to study their physiology at a molecular level. This is especially true for tissues such as the midgut, which forms the barrier between ingested material and the inside of the body.

Results: Here, we focus on the midgut of the southern green stink bug Nezara viridula and use both transcriptomic and proteomic approaches to create an atlas of expression along the four compartments of the anterior-posterior axis. Estimates of the transcriptome completeness were high, which led us to compare our predicted gene set to other related stink bugs and Hemiptera, finding a high number of species-specific genes in N. viridula. To understand midgut function, gene ontology and gene family enrichment analyses were performed for the most highly expressed and specific genes in each midgut compartment. These data suggested a role for the anterior midgut (regions M1-M3) in digestion and xenobiotic metabolism, while the most posterior compartment (M4) was enriched in transmembrane proteins. A more detailed characterization of these findings was undertaken by identifying individual members of the cytochrome P450 superfamily and nutrient transporters thought to absorb amino acids or sugars.
\end{abstract}

Conclusions: These findings represent an initial step to understand the compartmentalization and physiology of the $N$. viridula midgut at a genetic level. Future studies will be able to build on this work and explore the molecular physiology of the stink bug midgut.

Keywords: Nezara viridula, Southern green stink bug, Transcriptomics, Proteomics, Midgut, P450, Transporter

\footnotetext{
* Correspondence: shane_denecke@imbb.forth.gr;

panagiotis_ioannidis@imbb.forth.gr

${ }^{1}$ Institute of Molecular Biology and Biotechnology, Foundation for Research

and Technology - Hellas, N. Plastira 100, GR-70013 Heraklion, Crete, Greece

Full list of author information is available at the end of the article
}

(c) The Author(s). 2020 Open Access This article is distributed under the terms of the Creative Commons Attribution 4.0 International License (http://creativecommons.org/licenses/by/4.0/), which permits unrestricted use, distribution, and reproduction in any medium, provided you give appropriate credit to the original author(s) and the source, provide a link to the Creative Commons license, and indicate if changes were made. The Creative Commons Public Domain Dedication waiver (http://creativecommons.org/publicdomain/zero/1.0/) applies to the data made available in this article, unless otherwise stated. 


\section{Background}

Insect pests pose a serious threat to food security, which has led to the widespread adoption of transgenic plants expressing insecticidal proteins (e.g. Bt toxins derived from Bacillus thuringiensis). These have proved largely effective in controlling chewing insect pests, but their success has paved the way for secondary pests, which are not affected by $\mathrm{Bt}$, to become a significant problem [1]. Secondary pests primarily come from the hemipteran order of insects and avoid Bt by feeding on phloem sap or directly on fruit. In particular, stink bug-related crop damage from polyphagous species such as Halyomorpha halys (brown marmorated stink bug), Acrosternum hilare (green stink bug), Euschistus hero (brown stink bug), and the southern green stink bug Nezara viridula have become a major problem [2]. Despite their widespread importance, much still remains unknown about their physiology especially at the genetic level.

A tissue of critical importance for insect physiology is the midgut, which interacts directly with the external environment by separating the gut lumen (outside of the body) from the hemolymph (inside the body). Structurally, the insect midgut is composed of a single-cell thick epithelial layer comprised of various cell types including enterocytes involved in absorption/secretion, enteroendocrine cells which produce enteropeptides, and stem cells that can replenish damaged or old cells [3, 4]. Despite these conserved basic features, the insect midgut differs substantially between orders and species ([5] see Fig. 1 therein). $N$. viridula has a midgut that can be divided into four morphologically distinct sections along its anterior-posterior axis termed M1 (extreme anterior) to the extreme posterior (M4), which is separated from the first three anterior portions by a selective valve [6]. Some physiological roles have been assigned to these compartments; M3 has been implicated in nutrient digestion and the M4 region has long been known to harbor symbiotic bacteria which appear to be essential for growth [7-9]. However, neither the physiological roles or expression profiles of these gut compartments are fully understood.

Principle among the physiological functions of the midgut is the absorption of nutrients. Insects initiate this process through digestive enzymes which breakdown macromolecules, such as proteins and sugars, into oligomers or monomers. Recently, the protease landscape of the N. viridula the entire midgut was described by both proteomics and transcriptomics, which revealed an abundance of cysteine proteases in the slightly acidic $N$. viridula midgut [10, 11]. Families of glucosidases thought to metabolize sugar molecules have also been found in the midgut of the pistachio stink bug Brachynema germari [12]. The absorption of these smaller molecules has so far not been described in stink bugs, but it can be inferred from other metazoa that they are taken into gut cells via transporter proteins. Several families of transporters have been implicated in amino acid transport, including the Amino Acid and Auxin Permease (AAAP), the Neurotransmitter:Sodium Symporter (NSS), the Amino Acid-Polyamine-Organocation (APC), and the Proton-dependent Oligopeptide Transporter (POT/PTR). Other groups, such as the Sugar Porter (SP), the Solute:Sodium Symporter (SSS), and the SWEET families have been implicated in sugar transport [13]. Different labs have adopted different nomenclatures for these transporters (see Additional file 5: Table S1), but this has not prevented several groups from identifying members of these transporter families in insects [14-16], although this has not been performed in any stink bug species.

While the midgut must actively absorb nutrients from the diet, it must simultaneously form a barrier that selectively excludes toxic xenobiotics such as plant secondary metabolites or insecticides [17]. One of the key mechanisms of regulating the penetration and toxicity of such molecules is through metabolism by xenobiotic-metabolizing enzymes such as cytochrome P450s (P450s), carboxylesterases, and glutathione-S transferases. Members of these families are present in the gut and chemically modify xenobiotics, which limits their uptake and often results in their detoxification. P450s are particularly well studied; upregulation of P450s in the midgut has often been found to underpin insecticide resistance [18-20]. Information on P450s in stink bugs is currently limited to one species Halyomorpha halys, where a preliminary identification and analysis has been performed [21, 22].

In order to better understand the genetics and physiology of the midgut of the southern green stink bug $N$. viridula, we performed a detailed characterization of transcript and protein expression along the anterior-posterior axis. The unigene set obtained from the transcriptome assembly included the vast majority of conserved insect genes, allowing for a large scale phylogenomic analysis that placed $N$. viri$d u l a$ as a sister species to the green stink bug $A$. hilare, with high confidence. Moreover, the filtered unigene set was used for an orthology analysis, by comparing $N$. viridula to other stink bugs as well as other hemipteran and holometabolan insects suggesting an increased fraction of speciesspecific genes. We further examined $N$. viridula gut physiology by identifying gene families and GO terms enriched in specific midgut compartments, concluding partially overlapping roles for different sections of the midgut. This detailed profiling of stink bug midgut expression should serve as a basis for more detailed molecular characterization of stink bug midgut physiology in future studies.

\section{Results}

\section{Overview of Transcriptome and proteome}

The four midgut sections of adult $N$. viridula individuals were dissected and each of these tissues were sequenced 


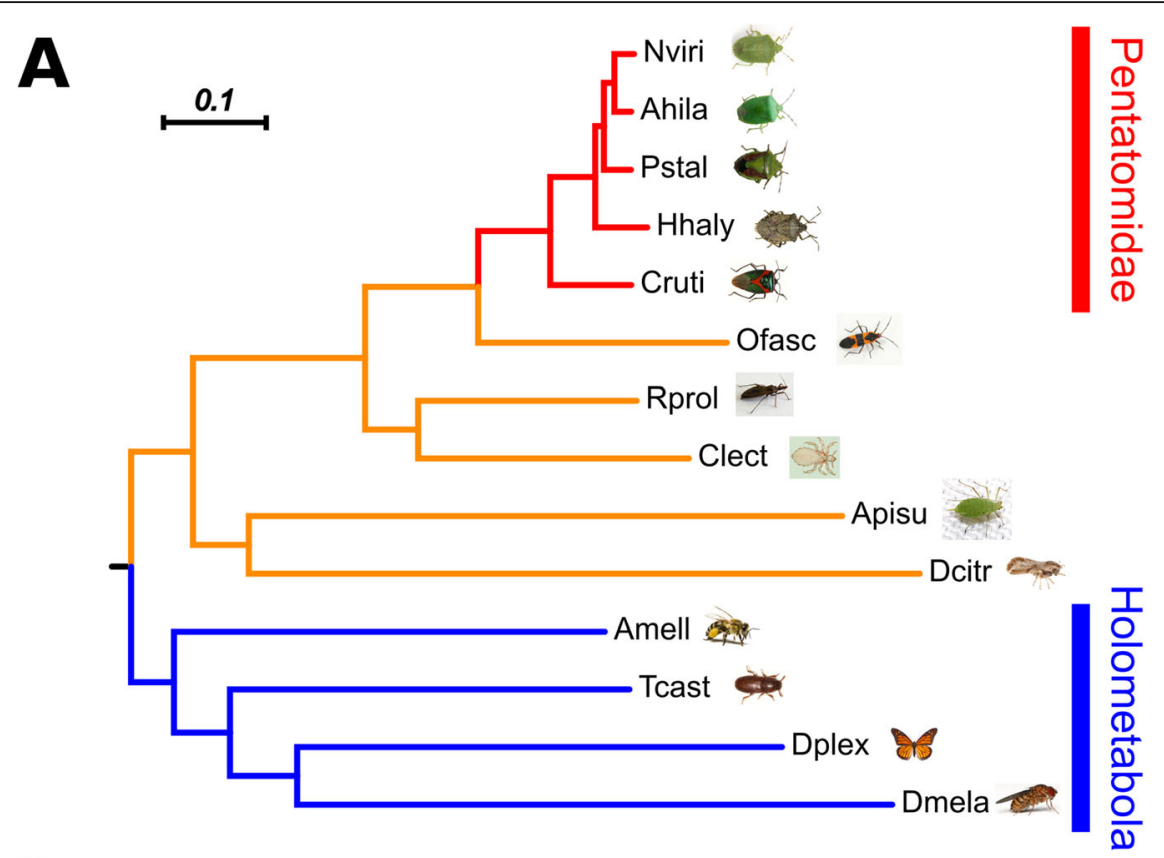

B

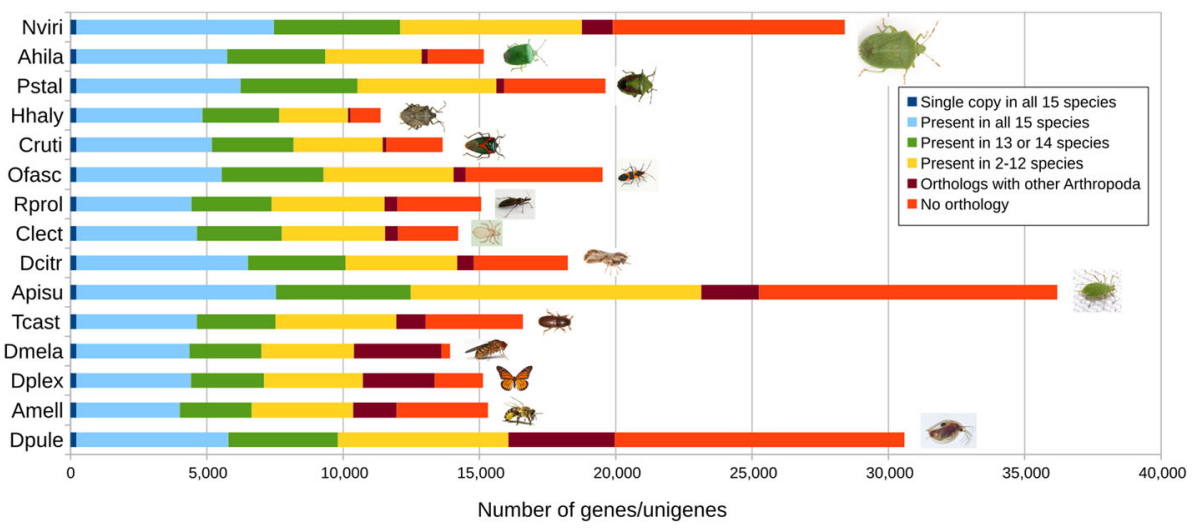

Fig. 1 Comparative gene sets among insects. a A phylogeny is shown constructed from 221 single-copy genes present in all species included in this analysis. The Pentatomidae (red) form a cluster within the Hemiptera (yellow) order which forms a sister clade to Holometabola (blue). The tree is rooted with the crustacean Daphnia pulex (not shown). Black dots indicate nodes with bootstrap support $>75 \%$, whereas gray dots indicate nodes with bootstrap support between 50 and $75 \%$. The scale bar is in substitutions per site. b Orthology profile of stinkbugs (names shown in red), compared to other insects. Note the large fraction of species-specific genes in N. viridula (Nviri) which is very similar to what has been previously documented for the pea aphid A. pisum (Apisu). Species names prefixed with " $\mathrm{T}$ ]" indicate that the unigene set was obtained from a transcriptome assembly; for the remaining insect species the data were obtained from a genome assembly. Species names abbreviations: Nviri - N. viridula; Ahila - A. hilare; Pstal - P. stali; Hhaly - H. halys; Cruti - C. rutilans; Ofasc - Oncopeltus fasciatus; Rprol - Rhodnius prolixus; Clect Cimex lectularius; Dcitr - Diaphorina citri; Apisu - A. pisum; Tcast - Tribolium castaneum; Dmela - Drosophila melanogaster; Dplex - Danaus plexippus; Amell - Apis mellifera

together with the corresponding carcass in four biological replicates yielding a total of $1,426,685,586$ reads. These were assembled de novo into 314,260 transcripts (Table 1), and running TransDecoder on this transcript set predicted a total of 73,752 peptides. This peptide set was used as the theoretical database to identify proteins from gel-free proteomics in each of the four midgut compartments, and resulted in a total of 3472 unique proteins in our samples (Table 1). No differences in terms of the enrichment of membrane proteins were observed between the supernatant and pellet fractions of the proteomic analysis (Additional file 6: Table S2). Lastly, we tested whether the presence/absence of a protein in the proteomics set was associated with its expression in the transcriptome and found that proteins identified in the proteome showed on average far higher 
Table 1 Statistics of transcriptome and proteome: An overview of the transcriptome and proteome is given in terms of total reads, contigs, unigenes, and detected proteins

\begin{tabular}{|c|c|c|c|c|}
\hline \multicolumn{5}{|c|}{ Transcriptome } \\
\hline & $\begin{array}{l}\text { Total } \\
\text { Reads }\end{array}$ & $\begin{array}{l}\text { Total } \\
\text { Contigs }\end{array}$ & $\begin{array}{l}\text { Total } \\
\text { unigenes }\end{array}$ & $\begin{array}{l}\text { Total non-bacterial } \\
\text { unigenes }\end{array}$ \\
\hline & $\begin{array}{l}1,426,685 \\
586\end{array}$ & 314,260 & 28,402 & 25,890 \\
\hline \multicolumn{5}{|c|}{ Proteome with bacterial-like transcripts } \\
\hline $\begin{array}{l}\text { Total } \\
\text { M1 }\end{array}$ & Total M2 & Total M3 & Total M4 & Total proteins \\
\hline 2401 & 1992 & 2472 & 2370 & 3472 \\
\hline \multicolumn{5}{|c|}{ Proteome without bacterial-like transcripts } \\
\hline $\begin{array}{l}\text { Total } \\
\text { M1 }\end{array}$ & Total M2 & Total M3 & Total M4 & Total proteins \\
\hline 2377 & 1968 & 2102 & 1945 & 3027 \\
\hline
\end{tabular}

expression values, compared to the non-detected proteins (Additional file 1: Figure S1). Full tables showing the expression levels reported in transcripts per kilobase million (TPM) and presence or absence in proteomics are reported in Additional file 7: Table S3 and Additional file 8: Table S4, respectively.

In order to perform a phylogenomic analysis, the $N$. viridula protein set was filtered to 28,402 unigenes by grouping transcripts at the gene level using the Trinity accession numbers, which yielded superior BUSCO scores (Additional file 2: Figure S2). This gene set was compared to publicly available genomes and transcriptomes from stink bugs and other insects (Additional file 9: Table S5). More specifically, we used the standalone version of the orthology database OrthoDB v9 [23] to obtain a list of 221 single-copy genes present in all species, which we subsequently used for a phylogenomic analysis. This analysis showed that all stink bugs clustered together and formed a monophyletic clade, as they all belong to the Pentatomidae family of Hemiptera (Fig. 1a). The phylogeny was complemented by an orthology analysis, in order to compare gene copy number across various insect lineages (Fig. 1b). Interestingly, the unigene set for $N$. viridula contained a large number $(n=8510)$ of unigenes that have no ortho$\log$ with other arthropod species. This number is elevated in $N$. viridula even when compared to the pentatomid stink bug $P$. stali that was analyzed using the same Trinity-based pipeline. The majority of these genes $(n=$ 5927 ) has a BLAST match (e-value $<1 \mathrm{e}-05)$ in the Uniref50 database, with almost half of them $(n=2378)$ being similar to an arthropod protein (Additional file 3: Figure S3). Of the 2583 genes that do not have a BLAST match in Uniref50, 1757 are transcribed with a TPM value $>1$, in at least one of the four midgut compartments, indicating that the corresponding genes should be further studied to determine whether they are functional.
It should be noted that a considerable fraction of the $N$. viridula unigene set are similar to bacterial proteins $(n=2512)$. These genes most probably originate from the bacterial symbionts associated with $N$. viridula. There was a significant difference in the mean transcriptional level of the gut regions, for 871 of them (one-way ANOVA tests using the log-transformed TPMs) with the vast majority being up-regulated in the M4 gut region, which harbors the bacterial symbionts in pentatomid stink bugs $[9,24]$. Most of these M4-specific genes originate from $\gamma$-proteobacteria, which is in agreement with previous studies $[9,25]$. Another set of genes appears as being expressed in the M1 and M2 regions only. Interestingly, their taxonomic profile differs from the previous ones, because their majority originates in the Bacteroidetes/Chlorobi clade. As this study was aimed at analyzing the midgut of $N$. viridula these 2512 bacteriallike genes were filtered out of the unigene set and all subsequent analysis was done on the set of 25,890 remaining eukaryote-like unigenes.

\section{Analysis of functions in each gut compartment}

In order to obtain an overview of the expression profile along the midgut, transcripts expressed $>1$ TPM and proteins detected with gel-free proteomics along the $N$. viridula midgut were compared visually with Venn diagrams (Fig. 2). Despite the obvious morphological differences of these segments, the majority of transcripts $(68 \% ; n=7898)$ and a significant amount of proteins $(43 \%, n=1302)$ were present in all compartments. In both analyses the M1 and M4 regions had the highest number of genes or proteins detected in only one compartment. To further explore the broad differences between midgut compartments we also performed a principle component analysis (PCA). The first two dimensions of the PCA explained 45.7 and $34.9 \%$ of the variation respectively (Fig. 3). All biological replicates in a sample clustered together, which is indicative of relatively high reliability of the tissue sampling. Also of note is the relative clustering of the M2, M3, and M4 sections especially along the first principle component, suggesting that these samples show similar transcriptome profiles. Unsurprisingly, the carcass sample clustered independently, but so also did the M1 section of the midgut suggesting that it has a distinct transcriptional profile to the other midgut sections. Collectively, these data suggest that while most genes detected in the analysis were commonly shared among all compartments, M4 and especially the M1 appear the most distinct.

A more detailed understanding of each midgut compartment was obtained by identifying groups of transcripts and analyzing them for enrichment in family membership (Pfam) or gene ontology (GO) terms. Fuzzy C-means clustering yielded eight groups of genes which displayed differing expression patterns along the midgut (Fig. 4). Four 
A

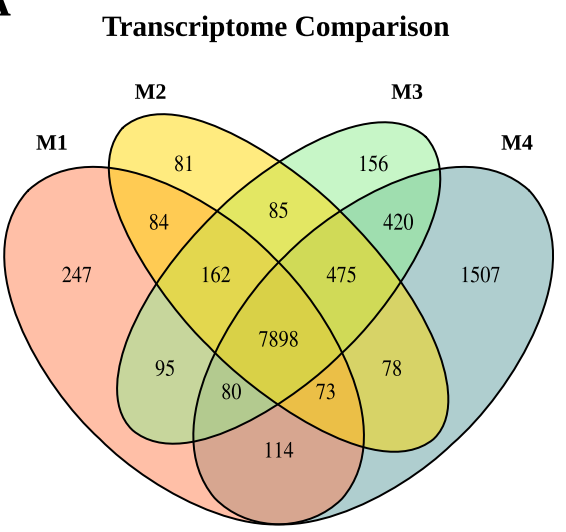

B

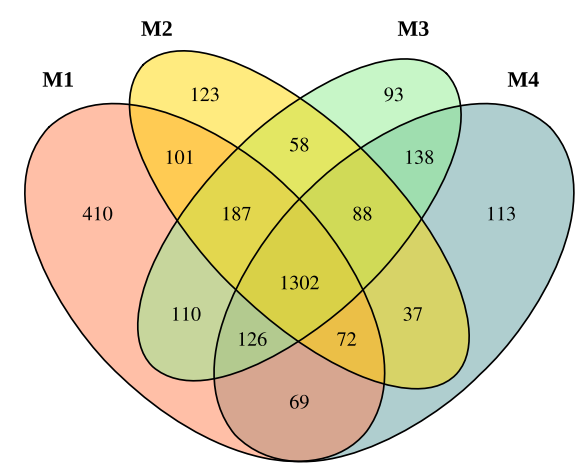

Fig. 2 Shared transcript and protein expression. Venn diagrams are shown for both detected transcripts (a) and proteins (b), showing expression $>1$ transcript per million (TPM) in each tissue. In each case, a sizable portion of the detected features are found across all midgut compartments, indicating a that many genes are expressed across the anterior-posterior axis. In both cases the M1 and M4 region display the most distinctiveness. The relatively lower number of proteins detected in the proteome compared to transcripts in the transcriptome is reflective of the sensitivities of these two technologies

out of the eight clusters reflected transcripts specific to a single compartment. The remaining four clusters showed more complex patterns of expression along the gut. For example, one cluster showed transcripts which gradually increased in expression level from anterior to posterior $(\mathrm{M} 1<\mathrm{M} 2<\mathrm{M} 3<\mathrm{M} 4)$. The 500 most highly expressed genes were also grouped from each compartment in order to estimate the predominant function of each section. These analysis yielded 12 groups of genes (8 clusters and 4 Top500 groups) which were analyzed in bulk by looking for enriched gene families and GO terms.

The M1-M3 region tended to display similar arrays of enriched protein families and GO terms with regards to both specificity and overall expression level. In the M1-M3 compartments families like cysteine proteases or GO terms related to proteolysis were found significantly enriched in both the top 500 most highly expressed genes and in the compartment specific cluster (Table 2; Additional file 10: Table S6). Likewise, families associated with xenobiotic metabolism (P450s, carboxylesterases) or GO terms associated with these reactions (oxidation-reduction process) were frequently found in the anterior sections. In contrast, the M4 displayed GO terms relating to transmembrane transporter proteins and an enrichment in proteins from the sugar porter family (PF00083; Table 2; Additional file 10: Table S6). Of all of the other clusters containing genes with more complex expression patterns, only one $(\mathrm{M} 1<\mathrm{M} 2<\mathrm{M} 3<$ M4) showed a significant enrichment in any GO term or family; the zinc finger $\mathrm{C} 2 \mathrm{H} 2$ family were overrepresented in this fuzzycluster. From the GO term and Pfam enrichment analysis it can be inferred that the anterior portion of the midgut (M1-M3) has a predominant role in metabolism of xenobiotics and nutrients, while the posterior has a role in the transport of nutrients.
Identification and analysis of detoxification enzymes and nutrient transporters

The enrichment of P450s in the anterior region of the midgut led us to annotate individual members of this gene family using a pipeline centered around homology searches. Testing our pipeline on several wellannotated proteomes, suggested that our method predicted a number of P450 genes that was close to those previously reported in the literature for other insects (Additional file 11: Table S7). After manually combining P450 fragments which displayed overlaps and removing contaminants, a total of 109 P450s were identified in our $N$. viridula unigene protein set (Fig. 5; Additional file 15; Additional file 12: Table S8). The expression profile of these P450s was then analyzed by family to observe any compartmentalization of functions. Of particular interest was the CYP6 family, which has a known role in insecticide metabolism [18] and showed high expression across all midgut compartments in our dataset with a clear enrichment in the anterior portion of the midgut (M1-M3) compared to both the M4 region and the carcass. Also of note were five CYP4G genes that are commonly implicated in cuticular hydrocarbon biosynthesis [26]. All four of these genes in $N$. viridula showed high levels of expression only in the carcass sample (Additional file 12: Table S8). Averaging the expression of all $\mathrm{P} 450 \mathrm{~s}$, there was roughly twice the expression in the anterior portions of the midgut compared to the posterior section.

The enrichment of transporter proteins in the M4 region of the midgut was expanded further by identifying individual members of several families of sugar and amino acid transporters using an in house pipeline (see Materials and Methods). Sugar transporters belonging to 


\section{Nezara Midgut Compartment PCA}

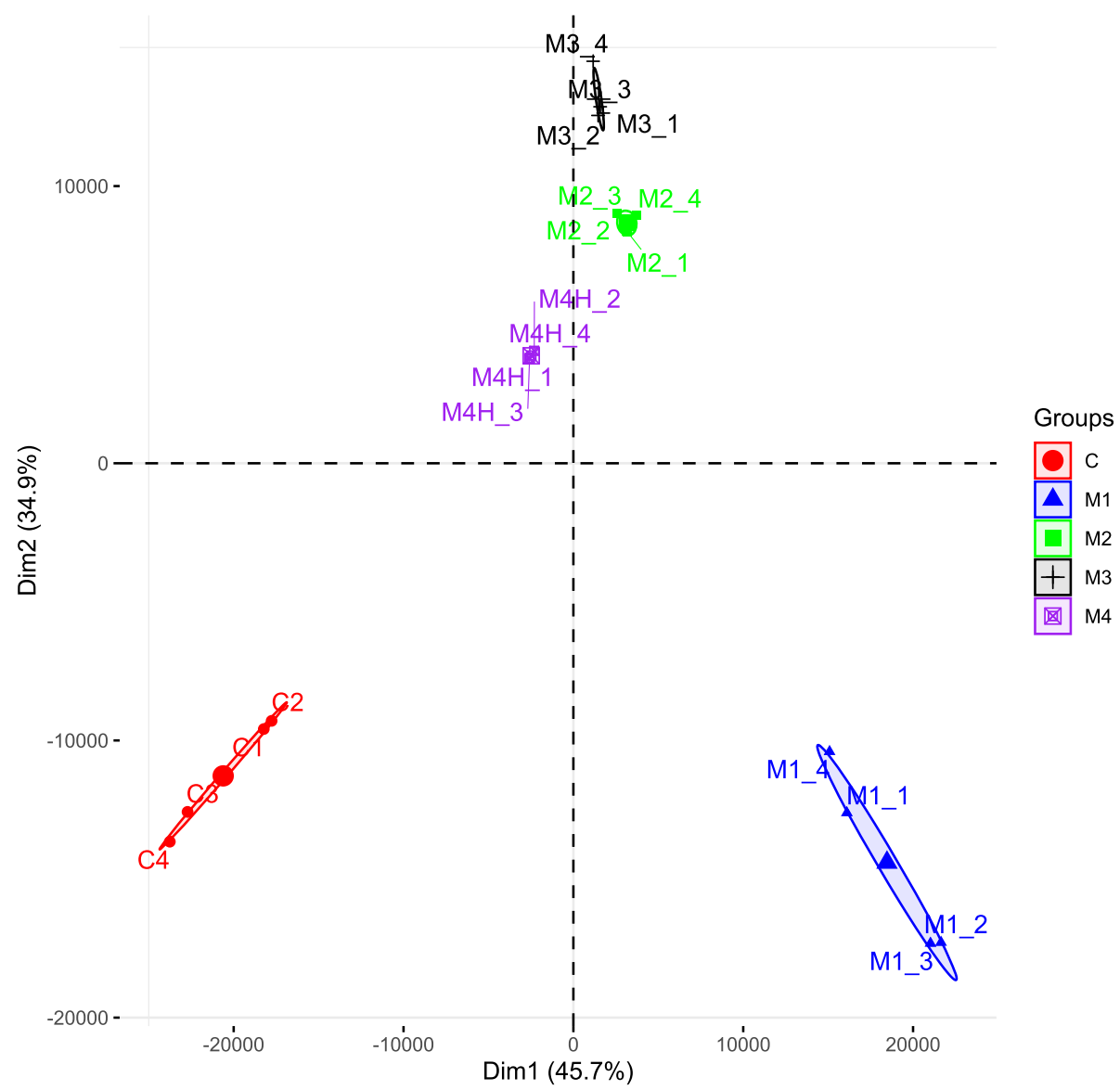

Fig. 3 Principle Component Analysis. The results of a principle component analysis of the expression of all unigenes is shown. The first two principle components explain a total of $78 \%$ of the total variation detected within the RNA-seq data. Each shape and color represent a distinct sample (M1: Blue triangle, M2: Green square, M3: Black cross, M4: purple crossed square, carcass: red circle). The variation in each sample is shown with an ellipse which encompass all replicates in that sample

the SP, SSS, and SWEET families were identified and analyzed for their expression pattern along the midgut (Additional file 16; Additional file 13: Table S9). The 11 SSS transporters that were identified, were expressed at very low levels in all midgut compartments. Only two SWEET transporters were detected, one of which showed high expression and 2-4 fold enrichment in all midgut compartments compared to the carcass. However, by far the largest group of sugar transporters was the SP family with 84 detected transporters. This group was incredibly diverse in its expression pattern; different SPs showed specificity or enrichment in different midgut compartments. However, in accordance with the Pfam enrichment of sugar transporters in the M4 region (Table 3), the highest total expression and the largest number of highly expressed genes (>50 TPM) were found in the M4 region of the midgut (Table 3).
Amino acid transporters belonging to the families NSS, APC, POT, and AAAP families were all represented by at least four members in $N$. viridula (Additional file 16; Additional file 13: Table S9). The ten NSS family members generally showed low expression, and only one NSS showed expression values of $>10$ TPM. The five POT family members showed a similar low expression apart from DN111091_c2_g2, which showed very high (> $200 \mathrm{TPM}$ ) expression in the M2 and M3 regions of the midgut. The APC and AAAP families were larger, with 18 and 15 members respectively. Furthermore, the number of transcripts from both APC and AAAP showing very high ( $>50 \mathrm{TPM}$ ) expression was elevated in the M4 tissue (Table 3); 3/15 AAAPs and 6/18 APCs were highly expressed in the M4 region. Lastly, the expression of these families in the M4 (APC: $48.00 \pm$ 15.4, AAAP: $85.9 \pm 26.8)$ and was higher than the 


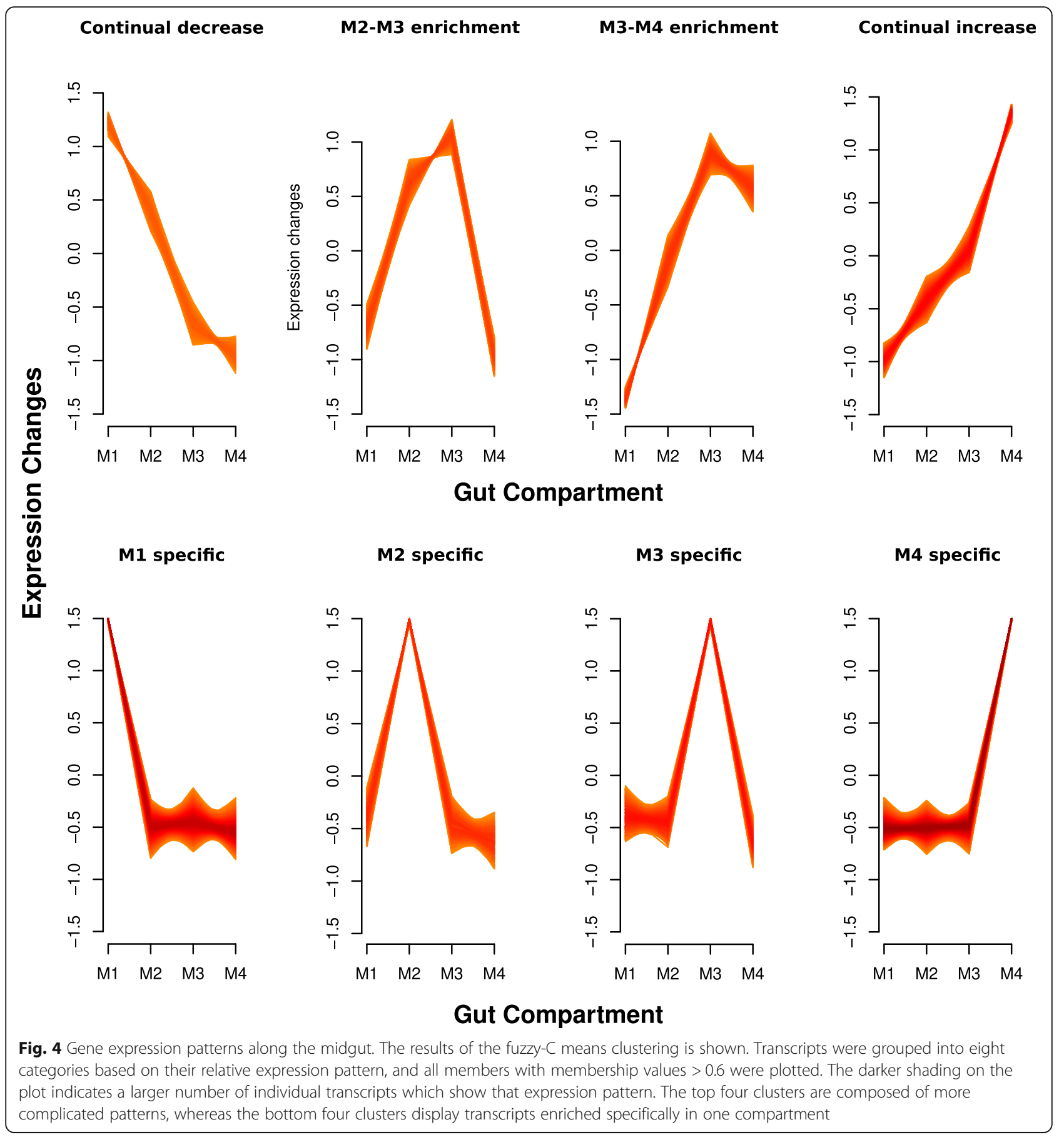

average anterior midgut expression (APC: $16.2 \pm 7.0$ : AAAP: $34.1 \pm 17.8$; Fig. 6 ).

\section{Discussion}

Stink bugs are an emerging threat to food security but are still poorly understood at the genetic level. Here, we aimed to provide basic genetic and physiological knowledge about the southern green stink bug $N$. viridula through RNA-seq and proteome sequencing with a strong focus on the midgut.

\section{Orthology and phylogeny}

Apart from specific information regarding midgut physiology, the completeness of our transcriptome (Additional file 2: Figure S2) allowed for an orthology analysis that included another three stink bug species with a publicly available genome or transcriptome (Fig. 1a, b). 
Table 2 A table is shown reflecting all of the significantly enriched GO terms from the gene groups produced from either the Fuzzy C-means clustering or the Top 500 most highly expressed genes in each sample. For each GO term, supporting information is provided such as the Gene Group from which it was identified the Code name, False discovery rate and information about how many genes with this term were identified compared to the total number in the transcriptome

\begin{tabular}{|c|c|c|c|c|c|}
\hline Gene Group & Code Name & $\begin{array}{l}\text { False Discovery } \\
\text { Rate }\end{array}$ & $\begin{array}{l}\text { \# of Genes in Group } \\
\text { with Term }\end{array}$ & $\begin{array}{l}\text { \# of Genes in Transcriptome } \\
\text { with Term }\end{array}$ & GO Term Annotation \\
\hline $\begin{array}{l}\text { Continual_increase_ } \\
\text { fuzzycluster }\end{array}$ & PF13909 & 0.000130095 & 23 & 189 & $\mathrm{C} 2 \mathrm{H} 2$-type zinc-finger domain \\
\hline $\begin{array}{l}\text { Continual_increase_ } \\
\text { fuzzycluster }\end{array}$ & $\begin{array}{l}\text { GO: } \\
0003676\end{array}$ & 0.000187859 & 69 & 1115 & nucleic acid binding, molecular_function \\
\hline M1_fuzzycluster & $\begin{array}{l}\text { GO: } \\
0006412\end{array}$ & 1.39345E-06 & 52 & 548 & translation, biological_process \\
\hline M1_fuzzycluster & PF02958 & $1.62758 \mathrm{E}-06$ & 19 & 85 & Ecdysteroid kinase \\
\hline M1_fuzzycluster & PF00112 & 0.000255183 & 17 & 110 & Papain family cysteine protease \\
\hline M1_fuzzycluster & PF00504 & 0.000255183 & 11 & 43 & Chlorophyll A-B binding protein \\
\hline M1_fuzzycluster & $\begin{array}{l}\text { GO: } \\
0008234\end{array}$ & 0.000504127 & 17 & 121 & $\begin{array}{l}\text { cysteine-type peptidase activity, molecular_ } \\
\text { function }\end{array}$ \\
\hline M1_fuzzycluster & $\begin{array}{l}\text { GO: } \\
0006414\end{array}$ & 0.000780785 & 11 & 56 & translational elongation, biological_process \\
\hline M1_Top 500 & PF00112 & $1.58324 \mathrm{E}-11$ & 19 & 110 & Papain family cysteine protease \\
\hline M1_Top 500 & $\begin{array}{l}\text { GO: } \\
0008234\end{array}$ & $2.43945 \mathrm{E}-11$ & 19 & 121 & $\begin{array}{l}\text { cysteine-type peptidase activity, molecular_ } \\
\text { function }\end{array}$ \\
\hline M1_Top 500 & PF00135 & $1.63518 \mathrm{E}-08$ & 15 & 100 & Carboxylesterase family \\
\hline M1_Top 500 & PF02958 & $1.13244 \mathrm{E}-06$ & 12 & 85 & Ecdysteroid kinase \\
\hline M1_Top 500 & PF00067 & 4.40651E-06 & 14 & 146 & Cytochrome P450 \\
\hline M1_Top 500 & $\begin{array}{l}\text { GO: } \\
0055114\end{array}$ & 0.000163275 & 37 & 1078 & $\begin{array}{l}\text { oxidation-reduction process, biological_ } \\
\text { process }\end{array}$ \\
\hline M1_Top 500 & $\begin{array}{l}\text { GO: } \\
0006508\end{array}$ & 0.000818748 & 18 & 394 & proteolysis, biological_process \\
\hline M2_fuzzycluster & PF00112 & $5.48524 \mathrm{E}-05$ & 11 & 110 & Papain family cysteine protease \\
\hline M2_fuzzycluster & $\begin{array}{l}\text { GO: } \\
0008234\end{array}$ & 0.000114662 & 11 & 121 & $\begin{array}{l}\text { cysteine-type peptidase activity, molecular_ } \\
\text { function }\end{array}$ \\
\hline M2_Top 500 & $\begin{array}{l}\text { GO: } \\
0055114\end{array}$ & 3.88423E-08 & 53 & 1078 & $\begin{array}{l}\text { oxidation-reduction process, biological_ } \\
\text { process }\end{array}$ \\
\hline M2_Top 500 & PF00112 & $2.93311 \mathrm{E}-07$ & 15 & 110 & Papain family cysteine protease \\
\hline M2_Top 500 & $\begin{array}{l}\text { GO: } \\
0008234\end{array}$ & 7.96227E-07 & 15 & 121 & $\begin{array}{l}\text { cysteine-type peptidase activity, molecular, } \\
\text { function }\end{array}$ \\
\hline M2_Top 500 & PF00067 & $9.31946 \mathrm{E}-07$ & 16 & 146 & Cytochrome P450 \\
\hline M3_Top500 & $\begin{array}{l}\text { GO: } \\
0055114\end{array}$ & $1.54695 \mathrm{E}-07$ & 51 & 1078 & $\begin{array}{l}\text { oxidation-reduction process, biological_ } \\
\text { process }\end{array}$ \\
\hline M3_Top500 & PF00067 & $4.50598 \mathrm{E}-05$ & 14 & 146 & Cytochrome P450 \\
\hline M3_Top500 & PF00135 & $4.50598 \mathrm{E}-05$ & 12 & 100 & Carboxylesterase family \\
\hline M4_fuzzycluster & $\begin{array}{l}\text { GO: } \\
0055085\end{array}$ & $1.64321 \mathrm{E}-13$ & 137 & 572 & $\begin{array}{l}\text { transmembrane transport, biological_ } \\
\text { process }\end{array}$ \\
\hline M4_fuzzycluster & $\begin{array}{l}\text { GO: } \\
0016021\end{array}$ & $1.03943 \mathrm{E}-10$ & 122 & 543 & $\begin{array}{l}\text { integral component of membrane, } \\
\text { cellular_component }\end{array}$ \\
\hline M4_fuzzycluster & PF12796 & $2.91941 \mathrm{E}-05$ & 83 & 387 & Ankyrin repeats (3 copies) \\
\hline M4_fuzzycluster & $\begin{array}{l}\text { GO: } \\
0008061\end{array}$ & 4.19023E-05 & 29 & 85 & chitin binding, molecular_function \\
\hline M4_fuzzycluster & $\begin{array}{l}\text { GO: } \\
0016020\end{array}$ & $5.10354 \mathrm{E}-05$ & 95 & 517 & membrane, cellular_component \\
\hline M4_fuzzycluster & PF00083 & 0.000120073 & 36 & 117 & Sugar (and other) transporter \\
\hline M4_fuzzycluster & $\begin{array}{l}\text { GO: } \\
0005515\end{array}$ & 0.000164315 & 307 & 2221 & protein binding, molecular_function \\
\hline M4_fuzzycluster & $\begin{array}{l}\text { GO: } \\
0006468\end{array}$ & 0.000464805 & 57 & 282 & $\begin{array}{l}\text { protein phosphorylation, biological_ } \\
\text { process }\end{array}$ \\
\hline
\end{tabular}




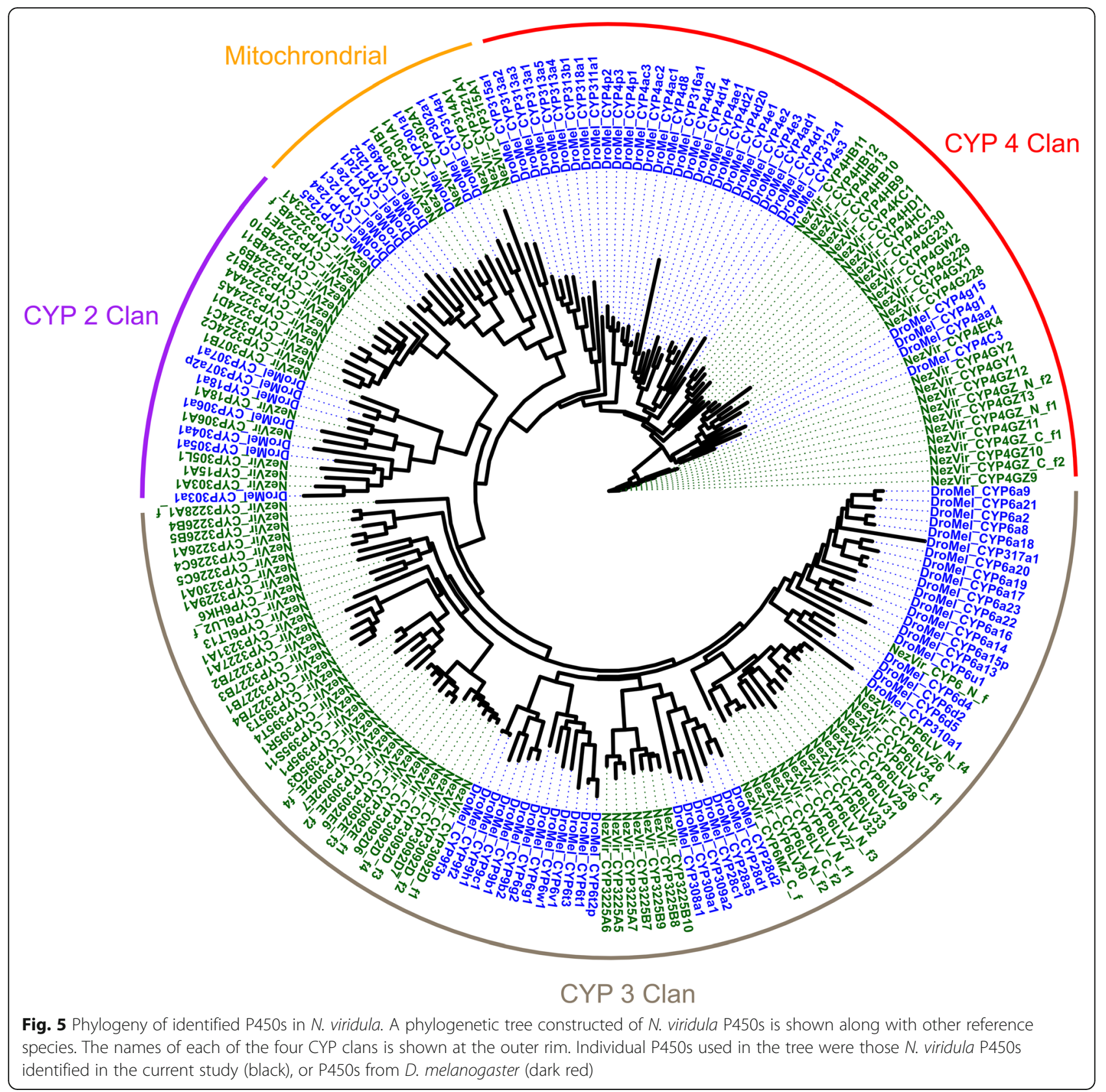

First, based on single-copy genes, this analysis showed that $N$. viridula is a sister species to $A$. hilare. Additionally, a high number of unigenes unique to $N$. viridula was identified compared to the other insects included in the comparison (Fig. 1b). Of course, this finding could be an artifact from the inherent limitations of de novo assembly of RNA-seq data. However, it should be noted that for three stinkbug species in this study (A. hilare, $C$. rutilans, and $P$. stali) de novo transcriptome assemblies were also used, but did not yield such high numbers of unique genes. While many of these genes are bacterial- like or are similar to transposable elements, excluding them still yields a large number of genes unique to $N$. viridula. Such lineage-specific genes are worth of further investigation because they might be associated with the particular ecological characteristics of the species.

A more detailed analysis of the bacterial symbionts is definitely needed, especially because they are essential for the survival of their host [9]. However, since our RNA extraction protocol was based on polyA selection, it specifically discarded the vast majority of bacterial transcripts. As a result, we hesitate analyzing further 
Table 3 Nutrient transporter expression in the midgut

\begin{tabular}{llllllll}
\hline Measuremnet & POT & APC & AAAP & NSS & SWEET & SSS & SP \\
\hline $\begin{array}{l}\text { Average M1 Expression } \\
\text { (TPM) }\end{array}$ & 32.73 & 12.60 & 22.67 & 2.60 & 56.08 & 0.84 & 36.89 \\
$\begin{array}{l}\text { Average M2 Expession } \\
\text { (TPM) }\end{array}$ & 103.55 & 18.06 & 49.53 & 2.08 & 46.17 & 0.26 & 36.73 \\
$\begin{array}{l}\text { Average M3 Expression } \\
\text { (TPM) }\end{array}$ & 152.57 & 17.88 & 30.03 & 2.01 & 40.04 & 0.70 & 26.94 \\
$\begin{array}{l}\text { Average M4H } \\
\text { Expression (TPM) }\end{array}$ & 33.04 & 48.00 & 85.90 & 9.07 & 34.44 & 5.17 & 54.84 \\
$\begin{array}{l}\text { Average Carcass } \\
\text { Expression (TPM) }\end{array}$ & 2.98 & 15.86 & 30.02 & 3.90 & 15.23 & 19.24 & 16.54 \\
$\begin{array}{l}\text { \# of M1 Transcripts } \\
\text { over 50 TPM }\end{array}$ & 1 & 1 & 1 & 0 & 1 & 0 & 9 \\
$\begin{array}{l}\text { \# of M2 Transcripts } \\
\text { over 50 TPM }\end{array}$ & 1 & 1 & 2 & 0 & 1 & 0 & 7 \\
$\begin{array}{l}\text { \# of M3 Transcripts } \\
\text { over 50 TPM }\end{array}$ & 1 & 1 & 1 & 0 & 1 & 0 & 4 \\
$\begin{array}{l}\text { \# of M4H Transcripts } \\
\text { over 50 TPM }\end{array}$ & 0 & 3 & 6 & 0 & 1 & 0 & 16 \\
$\begin{array}{l}\text { \# of Carcass Transcripts } \\
\text { over 50 TPM }\end{array}$ & 0 & 0 & 1 & 0 & 0 & 1 & 4 \\
\hline
\end{tabular}

After filtering for transcripts with <1 TPM in all compartments, average expression values were displayed along with the total number of highly expressed $>5$ and $>50>50$ TPM genes for each transporter family in each compartment these bacterial genes because such an analysis will have a reduced value, being based on an incomplete bacterial set of genes.

\section{The anterior midgut: M1-M3}

The anterior portions of the midgut (M1-M3) showed similar functional profiles according to the analysis performed in the current study. When considering groups of genes specific to a certain compartment or when selecting the most highly expressed genes, varying combinations of xenobiotic metabolizing enzymes (P450s and carboxylesterases), and cysteine proteases were found. This largely agrees with what has previously been shown for stink bug midguts in non-genetic studies; multiple groups have found that cysteine proteases predominate in the stink bug midgut and that their activity is enriched in the M1 and M3 regions [7, 10, 21, 27, 28]. Interestingly, the fact that enrichment in these proteases was found in multiple compartment-specific clusters of genes (Table 2) suggests that different individual members of these groups may be upregulated in different compartments. A further functional investigation of these sections of the midgut is needed, especially the M1 section. While possessing many of the same GO terms as the M2 and M3 section, this compartment had the most number of unique proteins detected and clustered apart from the M2 and M3 regions in the PCA
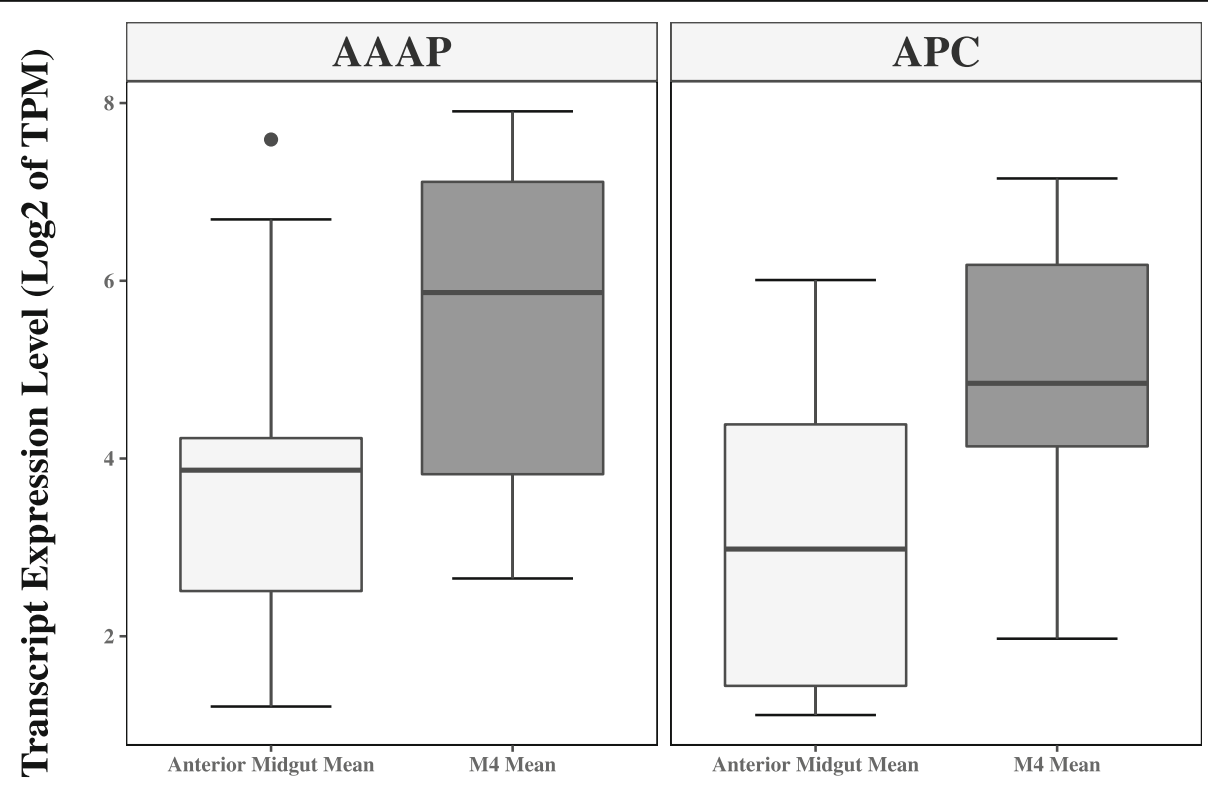

Gut Region

Fig. 6 Enrichment of AAAP and APC transporters in the M4 midgut region. A boxplot is shown comparing the expression of all AAAP and APC transporters showing along the midgut. Only genes showing expression above >1TPM in either the M4 region or the anterior region (average of the M1-M3 region) were plotted. The M4 region of the gut displays an enrichment in both APC and AAAP expression compared to the anterior section of the midgut 
presented here and in a parallel study considering the midgut transcriptomes of $N$. viridula midgut sections [29].

In order to gain a more detailed understanding of this compartmentalization of the M1-M3 region, we identified individual members of the cytochrome P450 family. Our analysis found a total of $109 \mathrm{P} 450 \mathrm{~s}$, significantly less than the $>160$ found in a closely related stink bug Halyomorpha halys [21]. However, this may be an artifact of the identification pipeline used in this study which predicted only 123 P450s in H. halys (Additional file 11: Table S7). Of particular interest are P450s that could cause insecticide resistance. More than 18\% (20/111) of P450s detected were in the CYP6 family known to have roles in insecticide metabolism in the midgut of other species [18, 20]. Additionally, these genes tended to have higher absolute expression in the midgut and were enriched in the M1-M3 regions compared to the M4 region or the carcass (Additional file 12: Table S8). The homology of these to known drug metabolizing enzymes and expression in a known metabolic tissue would place them on a shortlist of candidates for functional characterization of xenobiotic metabolism in vivo or in vitro.

\section{The posterior midgut: M4}

Previous physiological studies on the stink bug midgut have dealt primarily with the M4 region of the midgut, focusing in particular on symbiont-host interactions. The difficulty of gene manipulation in stink bugs has led to a focus on identifying bacterial factors that mediate symbiosis [6]. Some recent efforts have been made to understand host factors in the bean bug Riptortus pedestris, but differences in morphology between this insect and $N$. viridula (a bulb in the M4 region which appears to have specific properties), prevents a direct comparison with $N$. viridula [30,31].

The identification of nutrient transporters in the current study showed an enrichment of certain amino acid transporter families (APC and AAAP) in the symbiontcontaining M4 region (Fig. 6). While the exact role of the $N$. viridula symbionts has not been established, at least some of them appear to be essential for host survival [9], and the basis of this survival is thought to be in part due to the synthesis of essential amino acids [32]. Furthermore, the presence of symbionts in stink bugs is highly correlated with herbivory [8], suggesting that provision of essential amino acids underpins the fitness advantage conferred by these bacteria. It is thus tempting to speculate that increased expression of such transporters helps mediate the symbiotic interaction between bacteria and $N$. viridula as has been shown in the aphid-Buchnera symbiosis [32]. However, stink bugs lack aphid bacteriocytes (where these transporters have been localized to) and have a more promiscuous relationship with bacteria, so this comparison is not perfect. The role (or lack thereof) of these proteins in interacting with symbiotic bacteria awaits functional characterization.

\section{Conclusions}

In order to understand the function of an organism, tissue, or cell, one must first know the landscape of genes and proteins that are present there. While this study is purely descriptive in its nature, knowledge of the protein landscape of a tissue can provide a useful resource on which functional studies can build. This has been true in D. melanogaster where tissue-specific (FlyAtlas [33]; or intra-gut $[19,34,35]$ expression atlases have been used to address research questions beyond the scope of their original purposes. In addition to the atlas provided here, a parallel study (published while this manuscript was under review) has also sequenced several portions of the $N$. viridula midgut, which provides opportunities for comparisons and cross-validation [29]. Lastly, the recent validation of efficient RNAi in both $N$. viridula nymphs and adults, means that these resources can begin to be used to probe the molecular physiology of the stinkbug midgut.

\section{Methods}

\section{Insects and dissections}

A population of $N$. viridula was obtained from Bayer and bred for several generations at the Institute of Molecular Biology and Biotechnology (Heraklion, Greece). Adults were maintained on $12 \mathrm{~h}$ light:dark cycles at a temperature of approximately $23^{\circ} \mathrm{C}$ in mesh cages (Bugdorm, Taiwan). All individuals were raised in these cages with a mixture of organic sunflower seeds, carrots, and broad beans for food.

For the transcriptomic analysis, the four sections of the midgut (M1-M4; Additional file 4: Figure S4) were dissected from $N$. viridula adults in four biological replicates. Each biological replicate consisted of a single section of the gut take from at least 10 individuals, so RNA from 40 total midguts was sent for sequencing. The microscopic hindgut was included with the M4 region due to the inability to effectively separate these two tissues. The remaining non-midgut carcass was also collected and sequenced for comparative purposes. All tissues were dissected in RNAse-free phosphate-buffered saline (PBS) on ice, and RNA was extracted with the GeneJet RNA purification kit (Thermo Scientific) according to the manufacturer's instructions. Subsequently, all midgut samples were sent for strand-specific, paired-end sequencing using the Illumina HiSeq 2500 platform with $100 \mathrm{bp}$ per read (Macrogen Sequencing facility, Seoul).

For the proteomic analysis, the same four midgut parts were dissected and processed in three biological replicates by gel-free proteomic analysis at the Centre for Proteomics (Antwerp, Belgium) as was described elsewhere [36]. Each sample was split into membrane and supernatant 
protocols to in order to enrich for membrane bound vs soluble proteins respectively, and detected proteins from from both membrane and soluble fractions were pooled in order to generate a more complete protein set for each tissue. Finally, proteins were identified by the proteomics facility using a theoretical database which included the predicted peptides from the Trinity-based transcriptome assembly (see next section in Methods) and were further filtered so that we only obtain high-quality predictions by setting the threshold for the protein identification probability at $>95 \%$.

\section{Transcriptome processing and annotation}

Raw RNA-seq data were obtained in FastQ format and checked for quality with FastQC [37]. Assembly of reads was accomplished with Trinity v2.5.1 [38] using parameters for strand specific orientation (-seqType fq --SS_lib_type $\mathrm{RF})$. Both the nucleotide assembly and raw reads were deposited under the bioproject number PRJNA557118A corresponding protein set was generated using TransDecoder [39] with the default parameters. The resulting set of proteins was filtered in order to obtain a unigene set (one protein from each gene). To achieve this we made use of the Trinity naming scheme as it is encoded in the fasta accessions (e.g. TRINITY_DN1000_c115_g1_i1) and only kept the longest protein of each gene ("g") level as recommended by the Trinity manual. Finally, CD-HIT [40] was used to further filter this reduced protein set, by removing proteins that are entirely contained within larger proteins with the default word size and a sequence identity threshold of 1.0. Annotation of proteins and transcripts was accomplished by a combination of BLAST searches against the Uniref50 database [41] and protein domain identification with InterProScan [42]. Proteins having a significant similarity (evalue $<1 \mathrm{e}-05)$ to plant or bacterial sequences were discarded and not taken into account in downstream analyses.

Expression values for each unigene were obtained with Kallisto [43], which yielded normalized read counts in TPM. The mean TPM value for each transcript in each compartment was calculated by averaging the expression across the 4 biological replicates and was then used to perform comparisons of midgut function. Fuzzy C-means clustering was accomplished using the Mfuzz $\mathrm{R}$ package [44] which grouped all transcripts into eight clusters based on their expression pattern along the gut. All transcripts showing strong membership with a particular cluster $(\alpha$ values $>0.6$ ) were kept for further analysis. In parallel, the predominant function of each gut compartment was estimated by selecting the 500 most highly expressed genes (Top500) from each midgut compartment. All groups of genes from the Fuzzy C-means clustering and Top500 analysis were searched for their enrichment in gene families (Pfam) or GO terms using a custom R script implementing Fisher's exact test with a minimum number of genes, set at 10 and a false discovery rate of $<0.001$. The principle component analysis was accomplished by using the fviz_pca function in the factoextra R package.

\section{Phylogenomic analysis}

For the phylogenomic analysis we first mapped the above-mentioned $N$. viridula unigenes onto the ortholog groups of OrthoDB v9 [23], at the Arthropoda node. Additionally, we downloaded and processed the transcriptomes of another three stink bugs so that we only keep one isoform per gene; the brown-winged green stink bug Plautia stali [45], Chalcocoris rutilans [46], and the green stink bug $A$. hilare [46]. These processed transcriptomes were then mapped on OrthoDB. Subsequently, we used custom Perl scripts to find single-copy genes that were present in all stink bugs and also other insects covering some of the main insect orders. A custom RAxML-based pipeline was used for reconstructing the phylogeny, with the crustacean Daphnia pulex as the outgroup. In order to compare unigene sets between species, custom Perl scripts were used to identify different orthology profiles (single-copy in all species, present in all species, etc) in the selected insect species.

\section{Identification of P450s and nutrient transporters}

All P450s found in our dataset, were identified based on several criteria common in the literature. Briefly, a curated P450 fasta file containing sequences from Drosophila melanogaster, Apis mellifera, and Bombyx mori was downloaded and cleaned from the Cytochrome P450 homepage ([47]; www.p450-homepage.com). These genes were used as a query to search the $N$. viridula unigenes reported here using BLAST with an e-value cutoff of $1 \mathrm{e}-3$ and a query coverage of $>40 \%$. Unique hits from this list were then reciprocally searched with BLAST against the curated P450 fasta file, using the same parameters and were filtered for amino acid lengths of between 150 and 650 amino acids. These candidate proteins were further, further selected by presence of a PFAM P450 domain (PF000067). All P450s with overlapping sequence fragments were joined, and all P450s named in accordance with the established P450 nomenclature by Dr. David Nelson. A custom RAxML based pipeline was used to generate the phylogenetic tree using a maximum likelihood approach and 500 bootstraps. All $N$. viridula and D. melanogaster P450s were used in the tree, and visualization was accomplished using ggtree [48].

The identification of nutrient transporters is not fully standardized in insects. As all of these transporters are members of the SLC superfamily, a strategy was adapted from a previous publication [49] which identified novel SLC members in distantly related species. Human sequences from each transporter family were compiled from Bioparadigms (http://slc.bioparadigms.org/) and D. melanogaster family sequences were taken from the Flybase 
solute carrier gene groups [50] supplemented with manually curated additions. In each species, a HMM database was constructed for several sugar and amino acid transporter families (Additional file 5: Table S1) which were then used to search our Nezara protein sequences using the HMMer package [51]. Candidate transporters were further filtered by reciprocal blast and were considered to belong to a family as long as i) The top hit was in a particular family ii) 4 out of 5 of the top hits were in in that same family and iii) the query showed at least $20 \%$ similarity to one other member of that family. In cases where there were less than five predicted family members, it was sufficient that all members were in the top 5. Further filtering was done based on the presence of at least three transmembrane domains predicted by TMHMM [52]. In order to remove any abnormally short or long members of gene families, sequences were removed which had protein lengths more than one standard deviation from the minimum or maximum length of the corresponding protein family in humans and Drosophila which was modified from the filtering methodology of OrthoDB [23]. Candidates discovered using either human or $D$. melanogaster databases were then used to search the $N$. viridula unigene protein set iteratively.

\section{Supplementary information}

Supplementary information accompanies this paper at https://doi.org/10. 1186/s12864-020-6459-6.

Additional file 1: Figure S1. Comparison of transcript expression with protein detection. A boxplot comparing the output of the RNA-seq analysis with the proteomic analysis is shown. All unigenes were categorized as either "Present" or "Absent" in the proteome ( $x$ axis) and plotted according to their transcription level (y axis) in terms of log (base 2) transformed TPM value. These data suggest that genes detected in the proteome had generally higher transcript expression compared to those proteins that were not detected.

Additional file 2: Figure S2. Quality of the $N$. viridula transcriptome. An overview of the BUSCO-based analysis for the $\mathrm{N}$. viridula transcriptome are displayed. Fractions of single-copy (dark blue), multi-copy (light blue), fragmented (yellow), and missing (red) BUSCOs are shown. A) For the N. viridula transcriptome, the BUSCO analysis was run at the whole transcriptome, and also at the unigene set. The high BUSCO scores for the unigene set, together with the drastic reduction of duplicated BUSCOs compared to the whole transcriptome, show that it is suitable for for the downstream analyses, such as orthology and phylogeny analyses. B) The $N$. viridula unigene set was also compared against other available stink bug and Hemiptera gene sets. Importantly, all of the genomes and transcriptomes used in this work are of very good quality, as showed by the high BUSCO scores (> 80\% complete BUSCOs).

Additional file 3: Figure S3. Breakdown of the lineage-specific N. viridula unigenes. The $N$. viridula unigenes without orthologs are divided into sub-categories depending on their blast hits and transcriptional activity. Overall, the majority of these lineage-specific unigenes were not transcribed, which is more evident in the the genes that do not have a blast hit.

Additional file 4: Figure S4. A photograph of the $N$. viridula midgut. The $N$. viridula dissected midgut is shown with labels for each of the 4 sections. The photo was taken under a light microscope after dissection in PBS buffer after the diet described in the current manuscript.
Additional file 5: Table S1. Transporter nomenclature comparisons. An equivalency table is shown indicating the nomenclature of transporter families and their proposed substrates. Transporters are generally named according to their SLC family, Transporter Classification Database code (e.g. 2.A.22) or their common name, which indicates their general function.

Additional file 6: Table S2. Proteomics Enrichment. A comparison of the number of proteins identified during different protein extraction methods is shown. As the pellet sample is thought to be enriched in transmembrane proteins, comparisons were made between proteins with predicted transmembrane domains and others. However, no difference in membrane proteins was found among the two techniques.

Additional file 7: Table S3. Transcript TPMs. A full table of all unigenes identified in this study with their predicted expression (average TPM values across 4 samples) are shown for each midgut compartment along with an annotation based on Uniref50. Corresponding sequences for transcripts can be found in the bioproject PRJNA557118.

Additional file 8: Table S4. Full proteome. A full table of all unigenes identified in this study with an indication of whether the unigene was detected in the proteome of a given tissue. Corresponding sequences for transcripts can be found in the bioproject PRJNA557118.

Additional file 9: Table S5. Other Stink Bug Transcriptomes. A table showing information regarding the other stink bug transcriptomes used in this study. A unigene set was obtained from the sequenced $H$. halys genome while the other three stink bugs were assembled de novo using the same pipeline that was used for $N$. viridula. Accession numbers can be found in column 3 .

Additional file 10: Table S6. Gene Groups. A full list of all genes that were classified into one or more gene groups is shown. These groups were either derived from Fuzzy C-means clustering (Fig. 4) or from the top 500 most highly expressed genes in each tissue.

Additional file 11: Table S7. P450 Comparison. A table is shown which indicates the accuracy of the P450 identification pipeline used in the current study. A list of species with P450s already annotated (see references) were used as targets for the pipeline. The table also indicates the number of P450s predicted by our pipeline and the number previously shown in the literature.

Additional file 12: Table S8. P450 expression. A table is shown of all the P450s identified in our study. Corresponding information regarding sequence, P450 clan, name and expression values are also shown for each identified P450. NezVir_CYP6LV30 initially showed an extremely high TPM value (upwards of 2000), but manual inspection revealed this to be an artifact of the assembly, so it was excluded from the analysis.

Additional file 13: Table S9. Transporter expression. The full list of nutrient transporters and their corresponding expression values are shown. The table is broken down into transporters which act on amino acids/peptides and sugars. Corresponding information about the family to which the transporter belongs is also included.

Additional file 14: Table S10. BUSCO Scores. The Benchmarking Universal Single-Copy Orthologs (BUSCO) scores for each of the stink bug gene sets used in this study are shown. For each stink bug the differnet outputs of BUSCO are shown including, Complete and single-copy, Complete and multi-copy, Fragmented, and Missing.

Additional file 15. P450 sequences. All P450 sequences identified in this study are listed in fasta format.

Additional file 16. Transporter sequences. All transporter sequences identified in this study are listed in fasta format.

\section{Abbreviations}

AAAP: Amino acid and auxin permease; APC: Amino Acid-PolyamineOrganocation; GO: Gene ontology; NSS: Neurotransmitter:Sodium Symporter; POT: Proton-dependent Oligopeptide Transporter; SLC: Solute Carrier; SP: Sugar Porter; SSS: Solute:Sodium Symporter; TPM: Transcripts per kilobase million 


\section{Acknowledgments}

The authors would like to thank Dr. David Nelson for naming the P450s of N. viridula according to established nomenclature. Additionally, the authors must thank Christian Baden of Bayer AG for providing Nezara viridula insects on several occasions.

\section{Authors' contributions}

$\mathrm{SD}, \mathrm{PI}, \mathrm{BB}$, and PT performed computational analyses. SD drafted the manuscript with significant contributions from PI. Al performed dissections and RNA extractions. JV, VD, SG, and RN conceived of the project and coordinated it. All authors read and approved the final manuscript.

\section{Funding}

This work was funded as part of a collaborative project between Bayer Crop Sciences (Monheim, Germany) and the Institute of Molecular Biology and Biotechnology (Heraklion, Greece).

\section{Availability of data and materials}

The sequencing reads and de novo assembly are available from the Sequence Read Archive (SRA) under the bioproject accession PRJNA557118. Additional data and custom scripts ( $R$, bash, and python) are available upon request.

\section{Ethics approval and consent to participate}

Not applicable.

\section{Consent for publication}

Not applicable.

\section{Competing interests}

Authors SD, PI, and Al are funded as a part of a joint collaboration with Bayer Crop Sciences. Authors SG and RN are employed by Bayer Crop Sciences.

\section{Author details}

'Institute of Molecular Biology and Biotechnology, Foundation for Research and Technology - Hellas, N. Plastira 100, GR-70013 Heraklion, Crete, Greece. ${ }^{2}$ Bayer AG, Crop Science Division, R\&D Pest Control, 40789 Monheim, Germany. ${ }^{3}$ Department of Crop Science, Agricultural University of Athens, lera Odos 75, GR-11855 Athens, Greece. ${ }^{4}$ Department of Biological Applications and Technology, University of loannina, 45110 loannina, Greece.

\section{Received: 19 July 2019 Accepted: 7 January 2020}

\section{Published online: 06 February 2020}

\section{References}

1. Catarino R, Ceddia G, Areal FJ, Park J. The impact of secondary pests on Bacillus thuringiensis (Bt) crops. Plant Biotechnol J. 2015;13:601-12. https:// doi.org/10.1111/pbi.12363.

2. Esquivel J, Dmitry LM, Walker AJ, Wolfgang R, Jeremy KG, Michael DT, et al. Nezara viridula (L.). In: McPherson JE, editor. Invasive stink bugs and related species (Pentatomoidea). 1st ed. Boca Raton: CRC Press; 2018. p. 351-425. https://www.crcpress.com/Invasive-Stink-Bugs-and-Related-SpeciesPentatomoidea-Biology-Higher/McPherson/p/book/9781498715089.

3. Billingsley PF, Lehane MJ. Structure and ultrastructure of the insect midgut. In: Biology of the insect Midqut. Dordrecht: Springer Netherlands; 1996. p. 3-30. https://doi.org/10.1007/978-94-009-1519-0_1.

4. Huang J-H, Jing $X$, Douglas AE. The multi-tasking gut epithelium of insects. Insect Biochem Mol Biol. 2015;67:15-20. https://doi.org/10.1016/j.ibmb.2015. 05.004.

5. Engel P, Moran NA. The gut microbiota of insects - diversity in structure and function. FEMS Microbiol Rev. 2013;37:699-735. https://doi.org/10.1111/ 1574-6976.12025.

6. Ohbayashi T, Takeshita K, Kitagawa W, Nikoh N, Koga R, Meng X-Y, et al. Insect's intestinal organ for symbiont sorting. Proc Natl Acad Sci U S A. 2015;112:E5179-88. https://doi.org/10.1073/pnas.1511454112.

7. Sorkhabi-Abdolmaleki S, Zibaee A, Hoda H, Hosseini R, Fazeli-Dinan M. Proteolytic compartmentalization and activity in the midgut of Andrallus spinidens Fabricius (Hemiptera: Pentatomidae). J Entomol Acarol Res. 2013; 45:8. https://doi.org/10.4081/jear.2013.e8.
8. Kikuchi Y, Hosokawa T, Fukatsu T. An ancient but promiscuous host-symbiont association between Burkholderia gut symbionts and their heteropteran hosts. ISME J. 2011;5:446-60. https://doi.org/10.1038/ismej.2010.150.

9. Tada A, Kikuchi Y, Hosokawa T, Musolin DL, Fujisaki K, Fukatsu T. Obligate association with gut bacterial symbiont in Japanese populations of the southern green stinkbug Nezara viridula (Heteroptera: Pentatomidae). Appl Entomol Zool. 2011;46:483-8. https://doi.org/10.1007/s13355-011-0066-6.

10. Lomate PR, Bonning BC. Distinct properties of proteases and nucleases in the gut, salivary gland and saliva of southern green stink bug, Nezara viridula. Sci Rep. 2016;6:27587. https://doi.org/10.1038/srep27587.

11. Liu S, Lomate PR, Bonning BC. Tissue-specific transcription of proteases and nucleases across the accessory salivary gland, principal salivary gland and gut of Nezara viridula. Insect Biochem Mol Biol. 2018;103:36-45. https://doi. org/10.1016/J.IBMB.2018.10.003.

12. Ramzi S, Hosseininaveh V. Biochemical characterization of digestive aamylase, a-glucosidase and $\beta$-glucosidase in pistachio green stink bug, Brachynema germari Kolenati (Hemiptera: Pentatomidae). J Asia Pac Entomol. 2010;13:215-9. https://doi.org/10.1016/J.ASPEN.2010.03.009

13. Hediger MA, Clémençon B, Burrier RE, Bruford EA. The ABCs of membrane transporters in health and disease (SLC series): introduction. Mol Asp Med. 2013;34:95-107. https://doi.org/10.1016/.mam.2012.12.009.

14. Price DRG, Tibbles K, Shigenobu S, Smertenko A, Russell CW, Douglas AE, et al. Sugar transporters of the major facilitator superfamily in aphids; from gene prediction to functional characterization. Insect Mol Biol. 2010;19:97112. https://doi.org/10.1111/j.1365-2583.2009.00918.x.

15. Xia J, Yang Z, Gong C, Xie W, Pan H, Guo Z, et al. Genome-wide identification and expression analysis of amino acid transporters in the whitefly, Bemisia tabaci (Gennadius). Int J Biol Sci. 2017;13:735-47. https:// doi.org/10.7150/ijbs. 18153 .

16. Yang Z, Xia J, Pan H, Gong C, Xie W, Guo Z, et al. Genome-wide characterization and expression profiling of sugar transporter family in the whitefly, Bemisia tabaci (Gennadius) (Hemiptera: Aleyrodidae). Front Physiol. 2017;8:322. https://doi.org/10.3389/fphys.2017.00322.

17. Denecke S, Swevers L, Douris V Vontas J. How do oral insecticida compounds cross the insect midgut epithelium? Insect Biochem Mol Biol. 2018:103:22-35. https://doi.org/10.1016/JIBMB.2018.10.005.

18. Feyereisen R. Insect CYP Genes and P450 Enzymes. Insect Mol Biol Biochem. 2012:236-316. https://doi.org/10.1016/B978-0-12-384747-8.10008-X.

19. Harrop TWR, Pearce SL, Daborn PJ, Batterham P. Whole-genome expression analysis in the third instar larval midgut of Drosophila melanogaster. G3 (Bethesda). 2014;4:2197-205. https://doi.org/10.1534/g3.114.013870.

20. Denecke S, Fusetto R, Martelli F, Giang A, Battlay P, Fournier-Level A, et al. Multiple P450s and variation in neuronal genes underpins the response to the insecticide Imidacloprid in a population of Drosophila melanogaster. Sci Rep. 2017;7:11338. https://doi.org/10.1038/s41598-017-11092-5.

21. Bansal R, Michel A. Expansion of cytochrome P450 and cathepsin genes in the generalist herbivore brown marmorated stink bug. BMC Genomics. 2018;19:60. https://doi.org/10.1186/s12864-017-4281-6.

22. Mittapelly P, Bansal R, Michel A. Differential expression of cytochrome P450 CYP6 genes in the Brown Marmorated stink bug, Halyomorpha halys (Hemiptera: Pentatomidae). J Econ Entomol. 2019. https://doi.org/10.1093/jee/toz007.

23. Kriventseva EV, Tegenfeldt F, Petty TJ, Waterhouse RM, Simão FA, Pozdnyakov IA, et al. OrthoDB v8: update of the hierarchical catalog of orthologs and the underlying free software. Nucleic Acids Res. 2015;43: D250-6. https://doi.org/10.1093/nar/gku1220.

24. Kikuchi Y, Hosokawa T, Nikoh N, Meng X-Y, Kamagata Y, Fukatsu T. Hostsymbiont co-speciation and reductive genome evolution in gut symbiotic bacteria of acanthosomatid stinkbugs. BMC Biol. 2009;7:2. https://doi.org/10. 1186/1741-7007-7-2.

25. Prado SS, Almeida RPP. Phylogenetic placement of pentatomid stink bug gut symbionts. Curr Microbiol. 2009;58:64-9. https://doi.org/10.1007/s00284008-9267-9.

26. Balabanidou V, Kampouraki A, MacLean M, Blomquist GJ, Tittiger C, Juárez $M P$, et al. Cytochrome P450 associated with insecticide resistance catalyzes cuticular hydrocarbon production in Anopheles gambiae. Proc Natl Acad Sci U S A. 2016;113:9268-73. https://doi.org/10.1073/pnas.1608295113.

27. Bigham M, Hosseininaveh V. Digestive proteolytic activity in the pistachio green stink bug, Brachynema germari Kolenati (Hemiptera: Pentatomidae). J Asia Pac Entomol. 2010;13:221-7. https://doi.org/10.1016/J.ASPEN.2010.03.004.

28. do CQ FM, Terra WR, Moreira NR, Zanuncio JC, Serrão JE. Ultrastructure and immunolocalization of digestive enzymes in the midgut of Podisus 
nigrispinus (Heteroptera: Pentatomidae). Arthropod Struct Dev. 2013;42:27785. https://doi.org/10.1016/j.asd.2013.03.002.

29. Cantón PE, Bonning BC. Proteases and nucleases across midgut tissues of Nezara viridula (Hemiptera:Pentatomidae) display distinct activity profiles that are conserved through life stages. J Insect Physiol. 2019;119:103965. https://doi.org/10.1016/J.JINSPHYS.2019.103965.

30. Futahashi R, Tanaka K, Tanahashi M, Nikoh N, Kikuchi Y, Lee BL, et al. Gene expression in gut symbiotic organ of stinkbug affected by extracellular bacterial symbiont. PLoS One. 2013;8:e64557. https://doi.org/10.1371/journal. pone.0064557.

31. Kim JK, Kim NH, Jang HA, Kikuchi Y, Kim C-H, Fukatsu T, et al. Specific midgut region controlling the symbiont population in an insect-microbe gut symbiotic association. Appl Environ Microbiol. 2013;79:7229-33. https:// doi.org/10.1128/AEM.02152-13.

32. Price DRG, Feng H, Baker JD, Bavan S, Luetje CW, Wilson ACC. Aphid amino acid transporter regulates glutamine supply to intracellular bacterial symbionts. Proc Natl Acad Sci U S A. 2014;111:320-5. https://doi.org/10. 1073/pnas.1306068111.

33. Leader DP, Krause SA, Pandit A, Davies SA, Dow JAT. FlyAtlas 2: a new version of the Drosophila melanogaster expression atlas with RNA-Seq, miRNA-Seq and sex-specific data. Nucleic Acids Res. 2018;46:D809-15. https://doi.org/10.1093/nar/gkx976.

34. Buchon N, Osman D, David FPA, Fang HY, Boquete J-P, Deplancke B, et al. Morphological and molecular characterization of adult Midgut compartmentalization in Drosophila. Cell Rep. 2013;3:1755. https://doi.org/ 10.1016/j.celrep.2013.05.019.

35. Marianes A, Spradling AC. Physiological and stem cell compartmentalization within the Drosophila midgut. Elife. 2013;2:e00886. https:/doi.org/10.7554/eLife.00886.

36. Jonckheere W, Dermauw W, Zhurov V, Wybouw N, Van den Bulcke J, Villarroel CA, et al. The salivary protein repertoire of the Polyphagous spider mite Tetranychus urticae : a quest for effectors. Mol Cell Proteomics. 2016;15: 3594-613. https://doi.org/10.1074/mcp. M116.058081.

37. Andrews S. FastQC: a quality control tool for high throughput sequence data; 2010.

38. Grabherr MG, Haas BJ, Yassour M, Levin JZ, Thompson DA, Amit I, et al. Fulllength transcriptome assembly from RNA-Seq data without a reference genome. Nat Biotechnol. 2011;29:644-52. https://doi.org/10.1038/nbt.1883.

39. Haas BJ, Papanicolaou A, Yassour M, Grabherr M, Blood PD, Bowden J, et al. De novo transcript sequence reconstruction from RNA-seq using the trinity platform for reference generation and analysis. Nat Protoc. 2013;8:1494-512. https://doi.org/10.1038/nprot.2013.084.

40. Fu L, Niu B, Zhu Z, Wu S, Li W. CD-HIT: accelerated for clustering the nextgeneration sequencing data. Bioinformatics. 2012;28:3150-2. https://doi.org/ 10.1093/bioinformatics/bts565.

41. Suzek BE, Wang Y, Huang H, McGarvey PB, Wu CH. UniRef clusters: a comprehensive and scalable alternative for improving sequence similarity searches. Bioinformatics. 2015;31:926-32. https://doi.org/10.1093/ bioinformatics/btu739.

42. Jones P, Binns D, Chang H-Y, Fraser M, Li W, McAnulla C, et al. InterProScan 5: genome-scale protein function classification. Bioinformatics. 2014;30: 1236-40. https://doi.org/10.1093/bioinformatics/btu031.

43. Bray NL, Pimentel H, Melsted P, Pachter L. Near-optimal probabilistic RNA-seq quantification. Nat Biotechnol. 2016;34:525-7. https://doi.org/10.1038/nbt.3519.

44. Kumar L, Futschik ME. Mfuzz: a software package for soft clustering of microarray data. Bioinformation. 2007;2:5-7 http://www.ncbi.nlm.nih.gov/ pubmed/18084642. Accessed 3 May 2019

45. Nishide Y, Kageyama D, Yokoi K, Jouraku A, Tanaka H, Futahashi R, et al. Functional crosstalk across IMD and toll pathways: insight into the evolution of incomplete immune cascades. Proc R Soc B Biol Sci. 2019;286:20182207. https://doi.org/10.1098/rspb.2018.2207.

46. Johnson KP, Dietrich CH, Friedrich F, Beutel RG, Wipfler B, Peters RS, et al. Phylogenomics and the evolution of hemipteroid insects. Proc Natl Acad Sci U S A. 2018;115:12775-80. https://doi.org/10.1073/pnas.1815820115.

47. Nelson DR. The cytochrome p450 homepage. Hum Genomics. 2009;4:59-65 http://www.ncbi.nlm.nih.gov/pubmed/19951895. Accessed 3 May 2019.

48. Yu G, Smith DK, Zhu H, Guan Y, Lam TT-Y. ggtree : an r package for visualization and annotation of phylogenetic trees with their covariates and other associated data. Methods Ecol Evol. 2017;8:28-36. https://doi.org/10. 1111/2041-210X.12628.

49. Hoglund PJ, Nordstrom KJV, Schioth HB, Fredriksson R. The solute carrier families have a remarkably long evolutionary history with the majority of the human families present before divergence of Bilaterian species. Mol Biol Evol. 2011;28:1531-41. https://doi.org/10.1093/molbev/msq350.

50. Attrill H, Falls K, Goodman JL, Millburn GH, Antonazzo G, Rey AJ, et al. FlyBase: establishing a Gene Group resource for Drosophila melanogaster. Nucleic Acids Res. 2016;44:D786-92. https://doi.org/10.1093/nar/gkv1046.

51. Eddy SR. Accelerated profile HMM searches. PLoS Comput Biol. 2011;7: e1002195. https://doi.org/10.1371/journal.pcbi.1002195.

52. Krogh A, Larsson B, von Heijne G, Sonnhammer EL. Predicting transmembrane protein topology with a hidden markov model: application to complete genomes11Edited by F. Cohen J Mol Biol. 2001;305:567-80. https://doi.org/10.1006/jmbi.2000.4315.

\section{Publisher's Note}

Springer Nature remains neutral with regard to jurisdictional claims in published maps and institutional affiliations.
Ready to submit your research? Choose BMC and benefit from:

- fast, convenient online submission

- thorough peer review by experienced researchers in your field

- rapid publication on acceptance

- support for research data, including large and complex data types

- gold Open Access which fosters wider collaboration and increased citations

- maximum visibility for your research: over $100 \mathrm{M}$ website views per year

At BMC, research is always in progress.

Learn more biomedcentral.com/submissions 